\title{
Embolización arterial selectiva en un caso de carcinoma de células renales como alternativa terapéutica
}

\author{
J.E. Blasco Alfonso, Y. Pallás Costa, $M^{a}$ D. Ferrer Puchol*, E. Hernández Montes* \\ Servicio de Urología. *Servicio de Radiodiagnóstico. Hospital General de Requena. Valencia.
}

Actas Urol Esp 2005; 29 (3): 314-317

\section{RESUMEN}

EMBOLIZACIÓN ARTERIAL SELECTIVA EN UN CASO DE CARCINOMA DE CÉLULAS RENALES COMO ALTERNATIVA TERAPÉUTICA

Presentamos un caso de carcinoma de células renales muy voluminoso en una paciente de avanzada edad y con pluripatología asociada. Dada la negativa familiar a realizar cirugia radical y el elevado riesgo quirúrgico se optó por practicar embolización tumoral arterial selectiva con partículas de polivinil alcohol (PVA). Tras 28 meses de seguimiento la paciente resulta asintomática y con excelente calidad de vida.

Concluimos que la embolización es una alternativa terapéutica eficaz en el control de la sintomatología para casos seleccionados.

Palabras clave: Carcinoma de células renales. Tratamiento. Embolización arterial.

\section{ABSTRACT \\ SELECTIVE ARTERIAL EMBOLIZATION IN A CASE OF RENAL CELL CARCINOMA LIKE THERAPEUTIC CHOICE}

We show a big renal cell carcinoma case in an aged woman with many pathology associated. In view of the family refuse to make the radical surgery and the high surgical risk we decided to apply transarterial embolization treatment with polivinil alcohol particles (PVA). 28 months later the patient becames with no symptoms and with high quality life.

We come to the conclusion that embolization is an effective therapeutic for the symptoms control in selectionated cases.

Keywords: Renal cell carcinoma. Treatment. Arterial embolization.

$\mathrm{E}_{\mathrm{s}}^{1}$ 1 carcinoma de células renales (CCR) representa el 2-3\% de todos los tumores malignos de la edad adulta ${ }^{1,2}$. La resección quirúrgica es el único tratamiento curativo y por tanto de elección en aquellos tumores con función renal contralateral normal.

La embolización percutánea del CCR fue propuesta por Lang en $1971^{3}$ e incorporada de modo práctico por Almgard et al. en $1973^{4}$. La embolización se utilizó en un primer momento como técnica complementaria de la cirugia para facilitar la nefrectomía radical reduciendo la pérdida hemá- tica y el tiempo quirúrgico. Posteriormente fue empleada como técnica paliativa en pacientes con tumores irresecables o con hematurias incoercibles.

Actualmente tanto la embolización prequirúrgica como la paliativa son raras ya que los nuevos métodos de imagen han permitido la detección más precoz del CCR, y por tanto, de tumores de menor tamaño y estadio. Mihara et al. ${ }^{5}$ describen en un screening con ecografia para la detección de CCR un $87 \%$ de tumores correspondientes a estadios pT1 y pT2. 
Presentamos un caso de CCR muy voluminoso $(9,2 \times 7,6 \mathrm{~cm})$ que debutó con hematuria franca anemizante en una paciente de edad avanzada que rechazó tratamiento quirúrgico. Practicamos embolización arterial selectiva del tumor con resultado excelente tras 28 meses de seguimiento.

\section{CASO CLÍNICO}

Paciente mujer de 84 años de edad con antecedentes de HTA, Hipertiroidismo, Diabetes Mellitus tipo II y sindrome de ansiedad. Remitida a la C. Externa de Urología desde el Servicio de Urgencias por un cuadro de hematuria franca monosintomática de varias semanas de evolución sin otra sintomatología asociada ni alteración del estado general.

La exploración física puso de manifiesto la presencia de masa palpable a nivel de fosa lumbar derecha. $\mathrm{El}$ abdomen fue blando y depresible.

El estudio ecográfico solicitado mostró gran masa sólida heterogénea en polo inferior del riñón derecho siendo el riñón contralateral normal. La vejiga presentó ecos internos compatibles con coágulos. El estudio cistoscópico resultó anodino.

Asimismo fueron practicados TAC abdominopélvico, $\mathrm{Rx}$ torax, bioquímica hemática $\mathrm{y}$ hemograma.

La TC (Fig. 1) mostró gran masa tumoral derecha de 9x10 cm heterogénea y con zonas hipodensas (áreas de necrosis) con distorsión del parénquima renal y su contorno, localizada en el

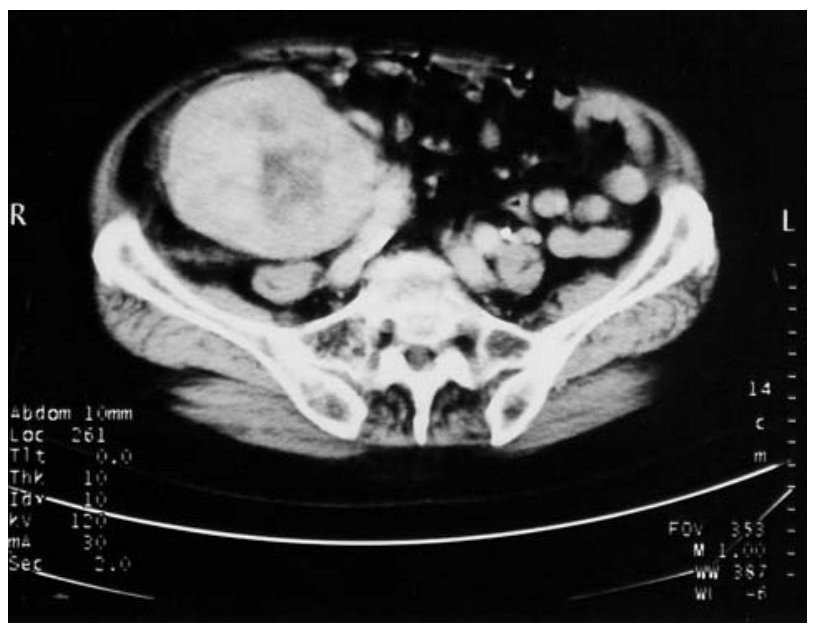

FIGURA 1. TC renal. Se observa gran masa tumoral renal derecha en polo inferior con signos de necrosis en su interior. polo inferior y con valores de atenuación inferiores a los del parénquima sano. La vena renal estaba trombosada y existían adenopatías locorregionales retroperitoneales.

A nivel analitico destacaron la presencia de anemia ferropénica, aumento de la VSG y normocalcemia.

Se propone cirugía radical que la paciente y la familia rechazan y como alternativa se acepta embolización selectiva.

Por punción en la arteria femoral común derecha se realiza arteriografia de aorta abdominal y posteriormente se cateteriza selectivamente la arteria renal derecha (Figs. 2 y 3) con un catéter angiográfico visceral Cobra 2 de 5 Fr, (Angiodinamics ${ }^{\circledR}$ ). A continuación se emboliza la arteria que irriga al tumor con partículas de alcohol de polivinilo (PVA) de 355 a 500 micras (Contour ${ }^{\circledR}$, Boston Scientific) ocluyendo totalmente el flujo de la misma (Fig. 4) y sin complicaciones inmediatas.

Tras 24 horas de hospitalización, dada la buena evolución de la paciente, se decide alta hospitalaria en espera de sucesivos controles.

A las 2 semanas postembolización la paciente consulta por cefalea realizándose TC cerebral que no muestra hallazgos de significación patológica. Tras 28 meses de seguimiento no se han vuelto a presentar episodios de hematuria y la única sintomatología destacable es insomnio y algia músculoesquelética, ambas controladas con

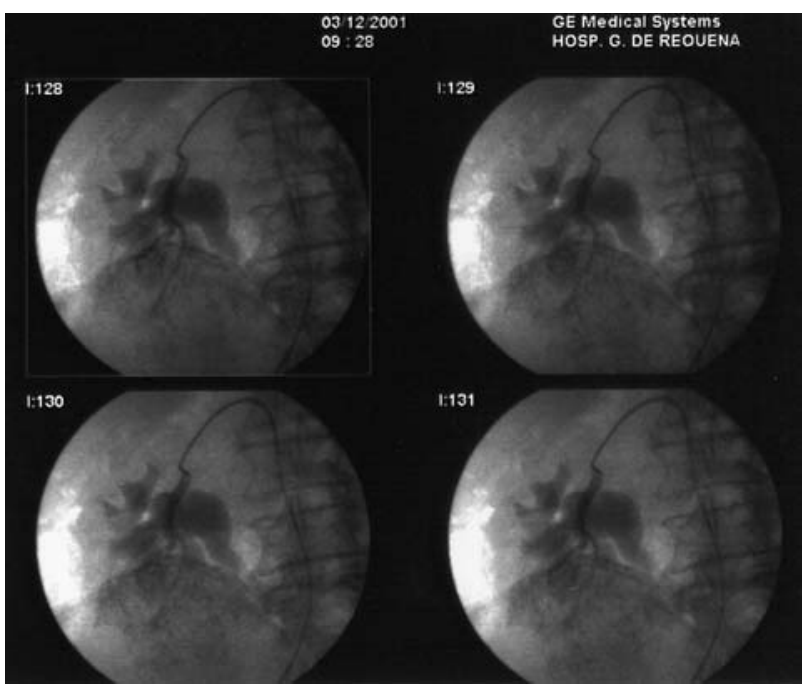

FIGURA 2. Imagen de Angiografia de la arteria renal derecha. Nótese la vascularización de la gran masa tumoral a cargo de un gran vaso principal. 


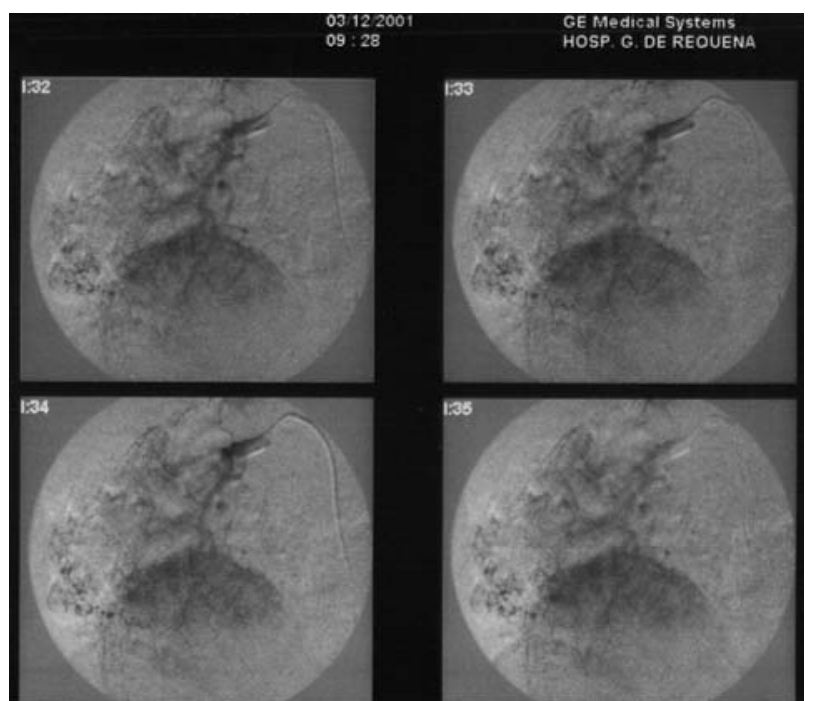

FIGURA 3. Angiografia con sustracción digital donde se identifican nitidamente la vascularización renal y tumoral.

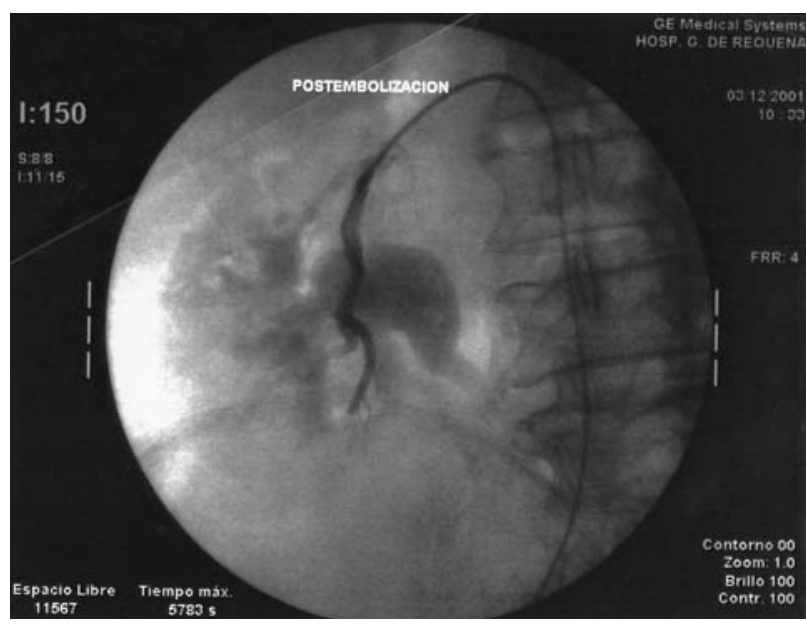

FIGURA 4. Imagen postembolización. Muestra la supre sión total del aporte vascular tumoral.

tratamiento sintomático. Los valores de tensión arterial no se han visto modificados manteniendo cifras aceptables con IECAS y calcio antagonistas.

\section{DISCUSIÓN}

El papel de la embolización en el CCR ha sido discutido durante varias décadas y es significativa la ausencia de estudios bien diseñados para clarificar sus indicaciones ${ }^{6}$. En la actualidad la técnica suele practicarse en dos casos fundamentalmente. Para facilitar la resección quirúrgica diminuyendo el tiempo de intervención y la pérdida hemática ${ }^{7}$ o de modo paliativo en pacientes con dolor, hematuria, síndrome paraneoplásico con alteración endocrina severa o clínica por efecto masa.
Algunos autores $1,3,8,9,10$ incluyen una tercera indicación y es cuando ciertos estadios tumorales no se consideran candidatos a cirugía. Nosotros apoyamos esta opción y más aún incluiríamos aquellos pacientes que por su avanzada edad, patología concomitante o simplemente negativa a cirugía radical podrían beneficiarse de un buen control de la sintomatología con el uso de ésta técnica.

Kalman $^{1}$ en 1999 realiza una excelente revisión sobre 51 publicaciones y un total de 3225 pacientes con CCR sometidos a embolización tumoral. Los autores corroboran que la indicación preoperatoria y paliativa son las más comunes obteniendo un buen resultado en el control de los síntomas en la mayoría de los casos. Asimismo establece que el intervalo de tiempo óptimo entre la embolización y la cirugía es de 24 horas.

No ha sido establecido que la embolización tumoral provoque regresión de las metástasis o suponga una prolongación de la supervivencia media siendo por término medio la expectativa de vida postratamiento de 38 meses $^{7,11}$.

El éxito del procedimiento y la técnica de embolización están supeditados a un perfecto conocimiento de la anatomía arterial renal del paciente por lo que es aconsejable el uso de la angiografia por sustracción digital, no sólo para un mejor control anatómico sino para reducir la cantidad de contraste empleado y la duración del procedimiento.

Las complicaciones de la embolización del CCR afectan al $10 \%$ de los pacientes con una mortalidad del 3,3\% ${ }^{6}$. Típicamente son autolimitadas y se controlan bien con tratamiento médico. El problema más habitual suele ser el síndrome postembolización con dolor lumbar, fiebre y náuseas. También han sido descritas pero con menor frecuencia HTA transitoria, aumento de los niveles de creatinina, ileo colónico, neumonía y absceso renal ${ }^{6,7,11}$. En nuestro caso la paciente presentó cefalea intensa como única complicación no inmediata que cedió con analgesia convencional resultando el TC cerebral normal.

En relación con la técnica, la embolización no deseada de otros órganos está descrita en un 9\% y se asocia a todos los materiales empleados. Dado que la circulación arterial renal es terminal, los materiales empleados producen isquemia o 
infarto. El espongostán es el material con menor riesgo y es de elección, junto con el alcohol, en la embolización prequirúrgica ${ }^{6}$. El empleo de partículas de PVA en la embolización paliativa se asocia a mayor índice de complicaciones, aunque no lo hemos observado en nuestro caso. El empleo de espirales metálicas se reserva generalmente para la embolización prequirúrgica presentando el inconveniente de que pueden migrar y no se controlan bien las colaterales.

La mayor parte de autores consultados ${ }^{5-7,9-12}$ coinciden en la necesidad de realizar ensayos controlados o estudios de cohortes prospectivos para poder comparar, en pacientes seleccionados, la indicación o no de la embolización selectiva.

Mientras eso ocurre nosotros coincidimos en aceptar la embolización como una alternativa terapéutica en el control de la sintomatología en aquellos pacientes que no deseen o no esté indicada la cirugía radical. Consideramos que, aunque no es una técnica exenta de riesgos y precisa de equipamiento radiológico y radiólogo intervencionista, debe de estar presente en el arsenal terapéutico del urólogo.

\section{REFERENCIAS}

1. Kalman D, Varenhorst E. The role of arterial embolization in renal cell carcinoma. Scand J Urol Nephrol 1999;33:162170 .

2. Hall WH, Megahan JP, Link DP, Devere White RW. Combined embolization and percutaneus radiofrecuency ablation of a solid renal tumor. AJR 2000;174:1592-1594.
3. Wallace S, Charnsangavej C, Carrasco $\mathrm{CH}$, Swanson DA. Embolization of malignant renal tumors. En Clinical Urography, Pollack HM: W.B. Saunders Company 1990; 30033017.

4. Almgard LE, Fernstron HM, Haverling M. Treatment of renal carcinoma by embolic occlusion of the renal circulation. Br J Radiol 1973;45:474-479

5. Mihara S, Kuroda K, Yoshioka R, Koyama W. Early detection of renal cell carcinoma by ultrasonographic screeningbased on the results of 13 years screening in Japan. Ultrasound Med Biol 1999;25(7):1033-1039.

6. Resel Estevez L, Moreno Sierra J. Tratado de Oncología Urológica 2003; Tomo I: 415-423.

7. Nurmi M, Satokari K, Puntala P. Renal artery embolization in the palliative treatment of renal adenocarcinoma. Scand J Urol Nephrol 1987:21(2):93-96.

8. Roy C, Tuchmann C, Morel M, Saussine C, Jacqmin D, Tongio J. Is there still a place for angiography in the management of renal mass lesions?. Eur Radiol 1999;9:329335.

9. Ray Ce. Renal Embolization. Semin Intervent Radiol 2001; 18(1):37-45.

10. Cina G, Lacquaniti S, Destito A, Di Stasi C. Preoperative percutaneus embolization in a case of spontaneus rupture of renal cell carcinoma. Br J Urol 1998;81:175-176.

11. Munro NP, Woodhams S, Nawrocki JD, Fletcher MS, Thomas PJ. The role of transarterial embolization in the treatment of renal cell carcinoma. BJU Int. 2003; Aug 92(3): 240-244.

12. Fichtner J, Swoboda A, Hutchenreiter G, Neuerburg J. Percutaneous embolization of the kidney: indications and clinical results. Aktuelle Urol 2003; Dec:34(7):475-477.

Dr. J.E. Blasco Alfonso

Avda. Manuel de Falla, 12 D - Esc. D - Pta. 12 46015 Valencia

(Trabajo recibido el 11 mayo de 2004) 